\title{
Modification and Performance Test of Prototype I Washer Machine
}

\author{
Wahyu Sugandi ${ }^{1}$, Asep Yusuf ${ }^{2}$, Asri Widyasanti ${ }^{3}$ \\ ${ }^{1}$ Department of Agriculture and Biosystem Engineering, Universitas Padjadjaran, Indonesia, sugandiwahyu@ gmail.com \\ ${ }^{2}$ Department of Agriculture and Biosystem Engineering, Universitas Padjadjaran, Indonesia, asep.yusuf@unpad.ac.id \\ ${ }^{3}$ Department of Agriculture and Biosystem Engineering, Universitas Padjadjaran, Indonesia, asriwidyasanti@ gmail.com
}

\begin{abstract}
The sweet potato (Ipomoea batatara L.) is one of the world's important tubers with a production of more than 133 million ton. In 2019, the Laboratory of Agricultural Equipment and Machinery designed a Prototype I Washer The machine is not optimal, reaching $67.13 \%$, and it needs to be modified because the skin of the sweet potato is cleaned and exfoliated so that it can reduce the quality of the sweet potato. The method used in this research is engineering, which is a non-routine design activity with new construction of process and product. Base on Matlab program, the result of the modification research and performance tests, is by using the prototipe I washer, the percentage of the level of cleanliness was $80.02 \%$. Where with an increase $67.13 \%$ using the performance machine. Based on the evaluation of technical feasibility and engine performance tests, it is found that the propulsion power needs $1 \mathrm{HP}$ and the deflection of the frame is only $13.06 \mathrm{~mm}$. The theoretical capacity of the engine is $231.68 \mathrm{~kg} \cdot$ hour $^{-1}$, the actual capacity is 100 kg.hour ${ }^{-1}$ with an efficiency of $44.39 \%$, the noise level of 77 $\mathrm{dB}$ and the engine vibration of $13.43 \mathrm{~m} \cdot \mathrm{s}^{-1}$.
\end{abstract}

Key words: modification, sweet potato, washing machines

\section{INTRODUCTION}

Sweet potato (Ipomoea batatara L.) is one of the world's important tubers with a production of more than 133 million tons, included in the seven important plant sources of carbohydrates after wheat, rice, corn, potatoes, barley and cassava [1].The sweet potato production center is the village of Cilembu District. Pamulihan District. Sumedang, West Java Province. Sweet potato is one of the potential agricultural products in Indonesia with a land area of about $178,121 \mathrm{ha}$. The average productivity of Indonesian sweet potato is 12,329 tons/ha, with a total production of 2,196,033 tons. The average productivity of sweet potatoes in West Java is 15,373 tons/ha, with a total production of 429,378 tons. Sweet potato plants can be harvested when the tubers are old (physiologically ripe). Short-lived sweet potatoes can be harvested at the age of 3-3.5 months, while long-lived varieties can be harvested at the age of 4.5-5 months. After the sweet potatoes are harvested, they can be sorted. Sorting is done to select clean, fresh and not defective tubers. Sorting can also be done at the time of extraction or harvest. Post-harvest handling of sweet potatoes is usually aimed at maintaining shelf life. The sweet potato is cleaned (washed or brushed) then let it air. Sweet potato storage should be done at a room temperature between $27-30 \mathrm{C}^{\circ}$ with humidity between $85-90 \%$. [2]

The washing process of Cilembu Sweet Potatoes in Cilembu Village, Pamulihan District, is currently by such as a cleaning process requires a relatively long time, namely 30 $\mathrm{kg}$.hour ${ }^{-1}$ with a need for 4 (four) workers.

\section{RESEARCH METHODS}

The research method used in this research is the engineering method, which is a design activity that is not routine, so that there is new construction in it, both in the form of a process and a product.[3]

\section{Tools and Materials}

The tools used for this research were a grinding machine (Makita, $11000 \mathrm{rpm}$ ), Electric Welding (Input power voltage 230 Volt, 250 Amp, 85\% efficiency Frado 230 volts, 250 amperes), Plate Folding Tool (EdwardsTruefolds, clamp length $2 \mathrm{~m}$ ), a laptop (HP Notebook 240 G6 i3-6006U 4GB 500 GB vg), CAM software (Solidworks 2018), Programming language software (Matlab R2014a), Calculator (Casio type $f x-82 E s$ ), a camera, a stopwatch (0.01-second accuracy), Digital Scale (maximum load 15 $\mathrm{kg}$ ), Tachometer (Krisbow K W06-302, accuracy $1 \mathrm{rpm}$ ), Sound level meter (Lutron SL-4010), Vibration cashew (Lutron VB-8200), Clamp-on-meter (Hioki 3286- 20).

The materials used in this study are divided into test materials and construction materials. The test material used in this study was Cilembu Sweet Potatoes used in washing testing.[4]

The research procedure carried out is presentedin figure 1. 


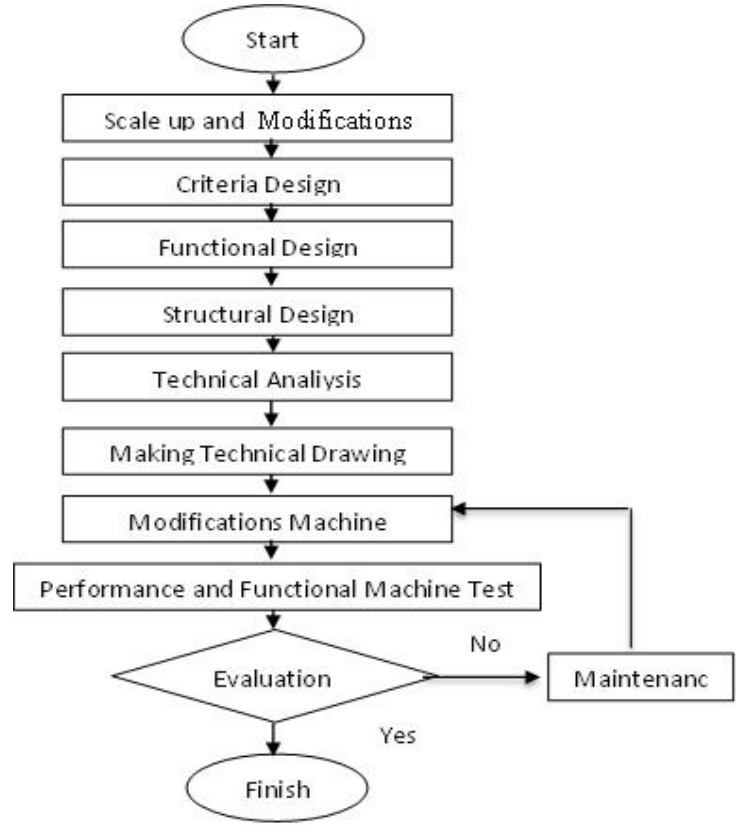

Figure 1. Research Flow Diagram

The stages of the research are as follows:

\section{Identification of Problems}

At this stage, data collection and supporting information are carried out. Data collection was done by making direct observations on the machine and by looking for machine deficiency information from machine washer prototipe 1 . The collected information data is used as a reference for determining the criteria for the modifications to be carried out.

\section{Design Criteria}

This stage was carried out after the problem identification result data was completed. The data obtained serve as a reference for making modifications. After analyzing existing problems and refining problem-solving ideas considering several related aspects, the formulation was carried out to produce several functional and structural design concepts equipped with sketch drawings and a technical analysis.[5]

\section{Functional Design}

This stage was the process in which the modified components were determined. Based on their function to meet predetermined modification criteria.

\section{Structural Design}

In structural design, the selection of shapes, sizes and placement of components selected was carried out. [5]

\section{Technical Analysis}

Technical analysis was carried out to determine the specifications of components that are safe for use on machines, to analyze machine mechanisms to be able to work according to criteria, and to find out safe limitations on machine operation.[6]

\section{Making Technical Drawing}

Technical drawings were made as a form of visualization of the based on the overall design and previous analysis. Technical drawings was also a guide in the modifications to the machine to be carried out next [4]

\section{Modifications}

At this stage, additional components were manufactured or adjusted to existing parts of the machine. Modifications were made based on the results of the previous design stage.

\section{Engine Performance Test}

The performance test was carried out to determine the work capability of the machine wash operated at optimum conditions. This is the basis for evaluating the machine. The testing stage is carried out to see whether the components used are functioning properly or not, furthermore this testing stage aims to test the capacity and quality of the results of washing sweet potatoes from the machine.[3]

\section{Evaluation}

The evaluation in this study was carried out based on the test results obtained. The results of the evaluation in this study are in the form of improvements. If the problems found are minor, while the repair of the problem requires a major overhaul, the modification results are only written in the discussion and research suggestions.

\section{A. Technical Analysis}

The technical aspects considered in the technical analysis of the prototype I washer was an analysis including: power requirements analysis, transmission system analysis, spi analysis, shaft analysis, frame strength analysis, weld strength analysis, and water flow analysis The analysis aims to determine the strength of the material from each machine component through theoretical calculations and direct treatments in the field.[7]

\section{B. Power Requirement}

An analysis of power requirements is carried out to determine the power required by the engine to run from start to finish, in transmission drive, cylinder rotation, and others. The propulsion requirement can be calculated by equation 1 [8]

Information :

$$
P=\frac{2 \pi \times M_{t} \times N}{60}
$$

$\mathrm{P}=$ The power needed to rotate the component (Watt)

$\mathrm{N}=$ Pulley rotation speed $(\mathrm{rpm})$

$M_{t}=$ Torque moment $(\mathrm{Nm})$

$$
\mathrm{M}_{\mathrm{t}}=\mathrm{F}_{\mathrm{t}} \times \mathrm{R}
$$

Information:

$\mathrm{M}=$ Torque moment $(\mathrm{Nm})$

$F_{t}=$ Tangential force $(\mathrm{N})$

$R=$ Radius $(\mathrm{m})$

Information :

$$
F_{t}=m \times g
$$

$m=$ Rotating component weight $(\mathrm{kg})$

$g=$ acceleration due to gravity $\left(\mathrm{m} . \mathrm{s} 2^{-1}\right)$

\section{Analysis of the Transmission Unit}

Analysis of the transmission unit aims to determine the number of belts and pulleys required in the engine transmission that are then matched with the required diameter of the transmission shaft. In determining the length of the belt used, it can be calculated using the comparison equation of the transmission in the belt and pulley transmission system, which can be calculated by equation 4 . [8] 
Information :

$$
\mathrm{L}=2 \mathrm{C}+\frac{\pi}{2}(\mathrm{D}+\mathrm{d})-\frac{1}{4 c}(\mathrm{D}-\mathrm{d})^{2}
$$

$\mathrm{L}=$ Belt length (mm)

$\mathrm{C}=$ Distance between pulley centers $(\mathrm{mm})$

$\mathrm{D}=$ Large pulley diameter $(\mathrm{m})$

$\mathrm{d}=$ Small pulley diameter $(\mathrm{m})$

The mass of the belt can be calculated using the following equation.

$$
m=\rho \times A \times L
$$

Information :

$\rho=$ Belt density $\left(1.14 \mathrm{~kg} . \mathrm{m} 3^{-1}\right)$

$\mathrm{A}=$ Belt cross-sectional area

The linear velocity of the belt can be calculated using the following equation[5].

$$
\mathrm{v}=\frac{\pi \cdot \mathrm{d} \cdot \mathrm{N}}{60}
$$

Information :

$\mathrm{d}=$ Small pulley diameter $(\mathrm{m})$

$\mathrm{N}=$ Small pulley speed $(\mathrm{rpm})$

\section{RESULTS AND DISCUSSION}

\section{A. Design Criteria}

The design criteria for the Prototype I Washer are as follows:

1. Cleaning brush cylinders and brush pads can reach the skin surface of Cilembu Sweet Potatoes.

2. The brush is made of nylon and can clean the Cilembu Sweet Potato from dirt without damaging the skin of the Cilembu Sweet Potato at a rotating speed.

3. The level of cleanliness of the Cilembu Sweet Potatoes is above $80 \%$.

4. The capacity of the Prototype II washer is $100 \mathrm{~kg} /$ hour.

5. Make a water channel to drain water into the cylinder.

6. The motor uses a $1 \mathrm{HP}$ electric motor.

\section{B. Functional Design}

The functional design is the design result of system component that has supporting functions to run the system. The main function of this machine is to clean the dirt that sticks to the skin of Cilembu sweet potatoes without damaging the skin. The functional design stage is carried out to determine what components are modified referring to the main mechanism and function systems that must be achieved by the machine by considering the level of cleanliness of Cilembu Sweet Potatoes and the operator's comfort. To get these results, several modified parts are needed with specific functions. .

\section{Structural Design}

The structural design is to determine the size and dimensions of each component selected. The structural design of each component must adjust and be selected based on the modified engine parts. The structural design aims to make the machine meet the requirements of a good machine, easy operation and good durability. (Figure 2,3 and 4)

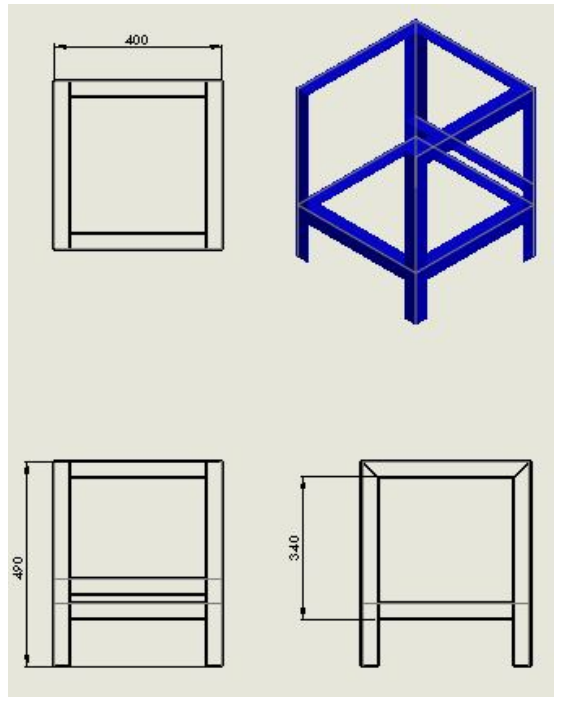

Figure 2.Machine Frame

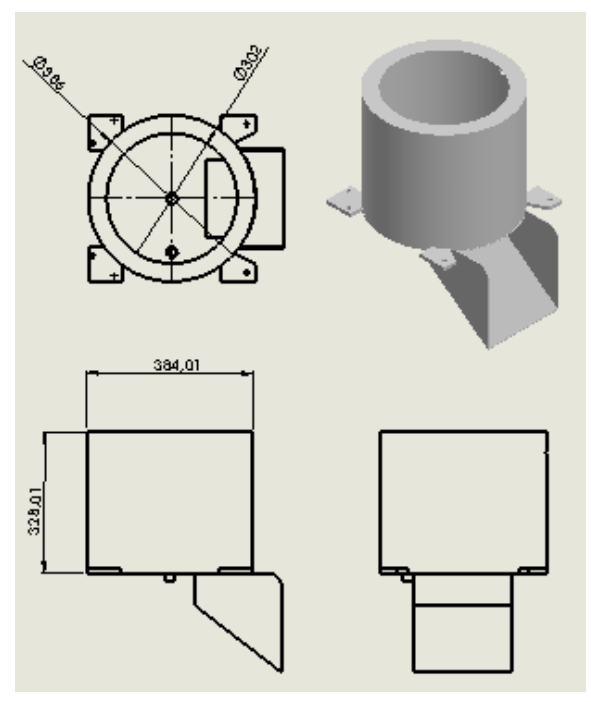

Figure 3. Washing Cylinder Tub
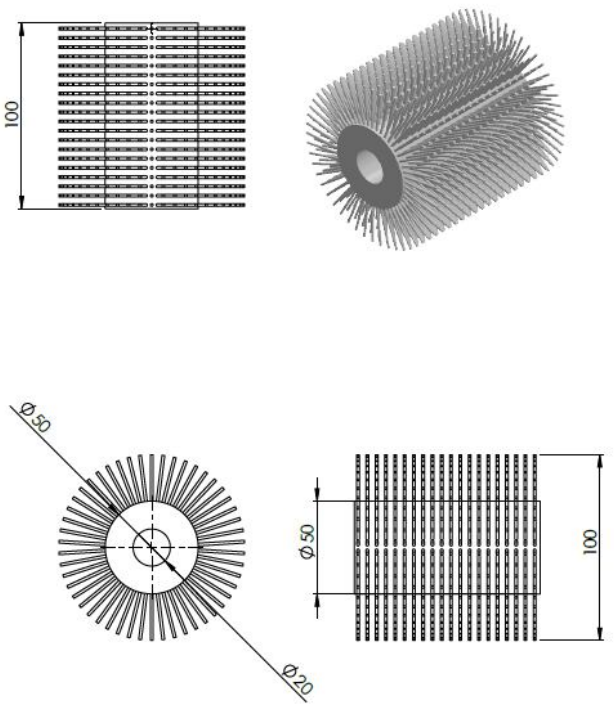

Figure 4.BrushCylinder 
The overall structural design is a combination of several components in one complete machine series with a customized layout (Figure 5). The overall structural design aims to make the machine meet requirements in terms of anthropometry, easy operation and safety when the operator is doing work.

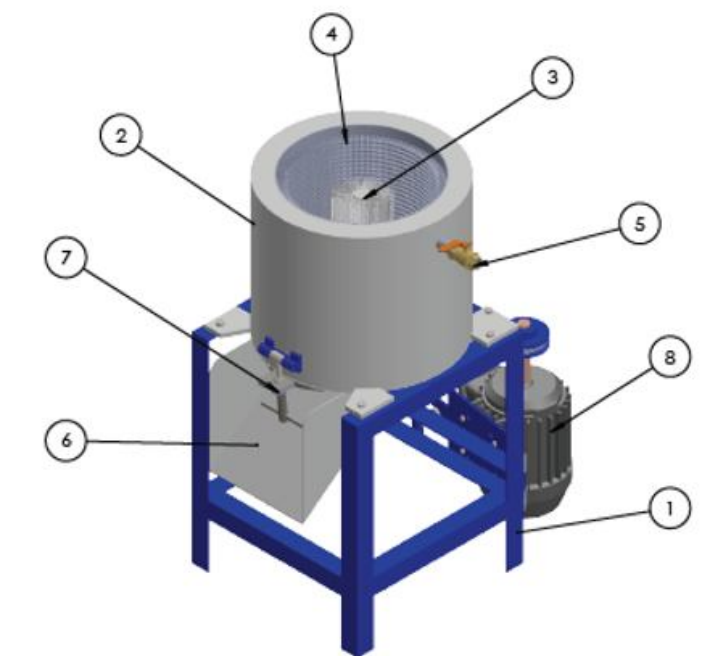

Information :

1.Frame

2. Cylinder tub

3. Cylinder brush

4. Bearing

5. Water way

6. Output

7. Cover lock

8. Electrik motor

Figure 5. Overall Design

\section{G. Modification of Sweet Potatoes Washer Machine}

Modifications made to this machine do not change the structure and function of the machine, but only add a few components to overcome the problem and maximize the performance of this sweet potato washing machine. The modification of the sweet potato washing machine is carried out on the brush cylinder by replacing a larger diameter, the drainage channel of the washing material by changing the dimensions of the washing material outlet, namely by enlarging the drain, and adding a water channel and a bearing or brush holder on the cylinder wall. The modified picture of the sweet potato washer is presented in figure6.a and 6.b.

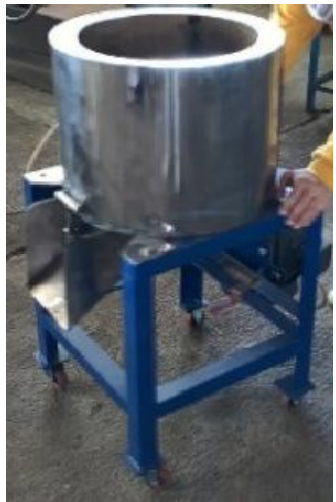

Figure 6.aBefore Modification

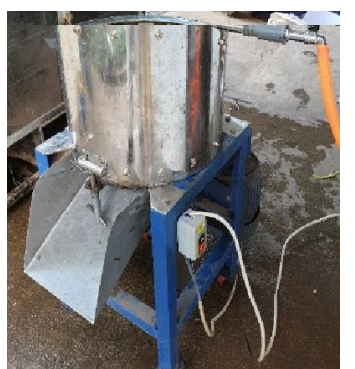

Figure6.bAfterModification

\section{CONCLUSION}

The conclusions of this study are as follows:

1. The modifications of Prototype I washer, are changing the diameter of the brush cylinder, changing the dimensions of the drainage channel of the washing product, adding a bearing or barrier to the inner cylinder wall and adding a water channel to drain the water.

2. The results of the modified performance test of the Prototype I washer showed that the engine performance was good. It shows that the theoretical capacity is 208.55 $\mathrm{kg} /$ hour, while the actual engine capacity is $120 \mathrm{~kg}$.hour 1 , engine efficiency is $66.29 \%$, power consumption is $0.280 \mathrm{~kW}$, specific energy is $11.01 \mathrm{~kJ}^{\mathrm{kg}}{ }^{-1}$, the noise level is $77 \mathrm{~dB}$, and engine vibration is $13,43 \mathrm{~m} . \mathrm{s}^{-1}$.

3 . This machine has met the technical requirements where the driving power requirement is 1922.18 Watt, the number of belts is 1 piece, the minimum shaft diameter is $17.6 \mathrm{~mm}$, the bearing life is 18629.852 hours, the size of spi is $18.75 \times 6.25 \times 6.25 \mathrm{~mm}$, and the deflection of the frame is only $1.306 \times 10^{-3}$.

4. In accordance with the results of the modification and performance tests, the percentage of the level of cleanliness obtained by using the Prototype I washer was $80.02 \%$. Where there has been an increase in the percentage level of cleanliness in the Prototype I Washer based on the use of the Matlab program. The ratio of the level of cleanliness of Sweet Potato washing using Prototype I washer to manual washing was $97.76 \%$. 
Wahyu Sugandi et al., International Journal of Emerging Trends in Engineering Research, 9(8), August 2021, 1086 - 1090

\section{ACKNOWLEDGMENT}

The author would like to thank profusely to the Universitas Padjadjaran, Ministry of Research and Technology/ National Research and Innovation Agency of the Republic of Indonesia for support of this publication

\section{REFERENCE}

1. Mahmudatussa'adah, A. (2014). Chemical Composition of Sweet Potato (Ipomoea batatas L) Cilembu at Various Storage Times as Raw Material for Liquid Sugar. Journal food Vol. 23 Issue 1, 53-54.

2. Suprapti, L. M. (2003). Sweet potato flour is made and used.KanisiusYogyakarta.

3. Sugandi, W., Zaida, Yusuf, A., Thoriq, A., Kramadibrata, A. (2018). Designing of Straw Chopper Machine for Compost Production. International Journal on Advanced Science, Engineering and Information Technology, Vol.8 Issue 5 https://doi.org/10.18517/ijaseit.8.5.5810

4. Sugandi, W., Yusuf, A., \& Widyasanti, A. (2019). Design of Cilembu Sweet Potato Cleaning Machine.International Journal of Innovative Technologyand Exploring Engineering Vol 9Issue 2.

5. Srivastava, A. K., Goering, C. E,. Rohrbach, R. P., Buckmaster, D. R. (2006). Engineering Principles of Agricultural Machines. American Society of Agricultural and Biological Engineers.

6. Singer, Andrew,Darwin. (1995). Strenght of Material.Erlangga, Jakarta.

7. Khurmi, R.S. (2002). Strength of Materials. Ram Nagar, New Delhi: S Chand \& Company Ltd.

8. Sularso, Kiyokasu dan Suga. (1978). Basic Planning and Design of Machine Elements. Pradnya Paramita. Jakarta. 